\title{
Comparison of shear bond strength of etch and rinse, self- etch adhesive system followed by flowable composite resin, and self-adherent composite resin
}

\author{
Myrna Nurlatifah Zakaria', Yuyun Andina Suri'1, Badi Soerachman'1, Khairul Anuar \\ Shariff' ${ }^{2}$ Arief Cahyanto ${ }^{3^{*}}$ \\ ${ }^{1}$ Department of Endodontology and Operative Dentistry, Faculty of Medicine Jenderal Achmad Yani \\ University, Indonesia \\ ${ }^{2}$ School of Materials and Mineral Resources Engineering, Engineering Campus of Universiti Sains \\ Malaysia, Malaysia \\ ${ }^{3}$ Department of Dental Materials Science and Technology, Faculty of Dentistry Universitas \\ Padjadjaran, Indonesia
}

\begin{abstract}
Introduction: The adhesive system strongly influences the bond strength of resin composite to the tooth surface. Aside from the commonly used etch and rinse, and self-etch adhesive system and a new approach called self-adherent composite resin to combine the adhesive system to the composite material. This study was aimed to compare the shear bond strength of two adhesive systems, (etch and rinse, selfetch adhesive system) followed by application of a flowable composite resin to a self-adherent resin composite. Methods: This study was experimental consisted of three groups of treatment, G1 (etch and rinse adhesive system+composite resin); G2 (self-etch adhesive system+composite resin), and G3 (selfadherent composite resin). Samples were 27 dentinal surfaces from premolar teeth bonded to composite resin ( $3 \mathrm{~mm}$ diameter and $3 \mathrm{~mm}$ in height), according to ISO technical specification No 11405. Shear bond strength test was performed using Universal Testing Machine (UTM) under the load of $50 \mathrm{kgf}$, and the crosshead speed of $0.5 \mathrm{~mm} / \mathrm{min}$, and the data was analysed by one-way ANOVA afterwards. Results: The highest bond strength to dentin was seen in Group 1 (14.89 MPa) followed by Group $2(11.65 \mathrm{MPa})$ and Group $3(11.22 \mathrm{MPa})$ with no significant difference between the three groups $p$ value $=0.117(p>0.05)$. Conclusion: The etch and rinse adhesive system had the highest shear bond strength to dentin, followed by the self-etch and the self-adherent composite resin. However, the shear bond strength of all tested groups was comparable.
\end{abstract}

Keywords: Shear bond strength, etch and rinse, self-etch adhesive system, self-adherent composite resin.

p-ISSN: 1979-0201; e-ISSN: 2549-6212; Available from: http://jurnal.unpad.ac.id/pjd/article/view/27989

DOI: 10.24198 /pid.vol32no3.27989

Submission: Jun 12, 2020; Accepted: Oct 6, 2020; Published online: Nov 30, 2020

"Corresponding author: Arief Cahyanto, Department of Dental Materials Science and Technology, Faculty of Dentistry Universitas Padjadjaran, Indonesia. Department of Dental Materials Science and Technology, Faculty of Dentistry Universitas Padjadjaran, Jalan Sekeloa Selatan I, Bandung, West Java, Indonesia, 40132. Phone: +6281219602295; Email: arief.cahyanto@fkg.unpad.ac.id 


\section{INTRODUCTION}

Bonding of composite resin restoration to the tooth structure is mainly affected by its adhesive system, which plays a significant part in forming a mechanical interlocking and chemical bond between the adhesive system and the enamel prism or dentinal tubule complex. Generally, the adhesive system is based on the same material with composite resin (monomer resin, matrix, filler, and coupling agent), but in small quantity or less than composite resin. The different structure of enamel and dentin makes the adhesive challenge even more challenging because of the moist and more organic component of dentin. Besides the adhesive properties to dry and moist structures, technique sensitivity, and time required to apply the adhesive system are also some considerations that take place in the adhesive technology development. ${ }^{1,2,3}$ Nowadays, composite resin adhesive systems either utilized the etch and rinse or self-adhesive system which has different adhesive mechanisms approach, however, both have performed successfully in clinical situations with different strengths and flaws in each system that are still clinically acceptable. ${ }^{3,4,5}$

The recent improvement of the resin composite adhesive technology is the selfadhering flowable composite resin that can be applied without application of the adhesive system to simplify the steps of the restoration. Self-adherent composite resin combines the adhesive system within the flowable composite resin, needing no surface pretreatment prior application of the flowable composite to the cavity. The material incorporates an acidic adhesive monomer into the composites. Thus its retention to the tooth structure is based on chemical and micromechanical interlocking action. The acidic monomer in the self-adherent composite, glycerolphosphate dimethacrylate (GPDM), is responsible for surface etching and chemical bond to calcium ions from the tooth by the acidic phosphate action, while the methacrylate component holds the polymerisation process and support the micromechanical interlocking mechanism between the monomer and demineralized collagen fibril of the dentin. ${ }^{6,7,8}$ As stated before, that bonding to enamel and dentin have different challenges, a study on the self-adherent resin composite bonding ability showed that self-adherent flowable resincomposite had lower bond strength to enamel and dentin than the total-etch (etch and rinse) system. ${ }^{7}$ In line with the mentioned results, bonding effectiveness of the self-adherent composite resin was also underscored to the self-etch adhesive system followed by the application of a flowable composite. ${ }^{9}$ A microscopic morphological evaluation by Scanning Electron Microscope (SEM) observation on the nanoleakage of the inter-face between the composite material and primary teeth dentin showed that the nanoleakage score between self-adherent composite is comparable to the conventional composite. However, the bond strength was less than the conventional ones. The sealing ability performance of the selfadherent resin composite is the same as the one using conventional flowable resin composite. ${ }^{10}$ However, the promising property of the selfadherent composite material in its simplification and time efficacy should not compromise the bonding effectiveness.

The bond strength of the adhesive system to tooth surfaces can be evaluated by the shear bond strength between the interface of the materials, which is one of the most common tests for adhesion between composite resin to email and dentin. The meas-urement can be used by micro or macro testing, depend on the size of the adhesion area. ${ }^{11,12}$ Study about self-adherent composite resin is mostly comparing the self-adherent composite resin to the self-etch adhesive system, with results that can differ from one another depending on the methods and material used. While bonding between self-etch adhesive system to conventional etch and rinse system mostly concluded that the simplified bonding steps in the self-etch system tend to reduce the bond strength, particularly to dentin structure. Therefore the etch and rinse adhesive system is still widely clinically used despite its longer step for application, however, postoperative sensitivities are more commonly reported using this system compared to the self-etch adhesive system, particularly in deep cavities. 13,14,15,16,17 Studies on the comparison of shear bond strength between etch and rinse adhesive system as the gold standard, self-etch adhesive system, and self-adherent composite resin are still limited. Therefore this study will compare the bonding strength of these 
three different bonding approaches to dentin structure. This study was aimed to compare the shear bond strength of two adhesive systems (etch and rinse, self-etch adhesive system) followed by application of a flowable composite resin to a self-adherent resin composite.

\section{METHODS}

A true experimental study using 27 extracted premolar teeth was conducted. Inclusion criteria for the samples were; extracted teeth collected from patients in the range of 15-25 years old, teeth were sound with no caries defect, fracture or traumatic defect and extracted for orthodontic treatment purpose, extraction time was less than three months of samples collection (Ethical Exemption from Health Research Ethics Committee, Faculty of Medicine, Universitas Padjadjaran No. 39/UN6.C.10/PN/2018). Samples were cut to the dento enamel junction (DEJ) site to gain exposed dentin surface and treated according to the restoration group. Samples with deformities after sample preparation or unsatisfied composite restoration were excluded from the study. Preparation for the samples was performed as follows: teeth were individually submerged to a self-cure acrylic resin for fixation.

Furthermore, the tooth in each acrylic resin was cut horizontally in the dentinoenamel junction (DEJ) area using a diamond disk bur to expose the dentinal occlusal surface at the DEJ. The exposed dentin surface was cleaned, and mould was placed on the dentin surface with a cylindrical mould ( 3 $\mathrm{mm}$ diameter and $3 \mathrm{~mm}$ height) to hold the flowable composite resin prior light polymerisation (Figure 1). The prepared samples were divided into three groups. Group 1: etch and rinse adhesive system + flowable resin composite (Eco-Etch $37 \%$ Phosphoric acid, Ivoclar Vivadent + Adper Single Bond, 3M ESPE + Flowable composite Z350 XT, 3M ESPE). Group 2: self-etch adhesive system + flowable resin composite (Single Universal Bond 3M ESPE + Flowable composite Z350 XT, 3M ES-PE). Group 3: Self-adherent composite resin (Dyad Flow Self Adhering Flowable Composite, Kerr).

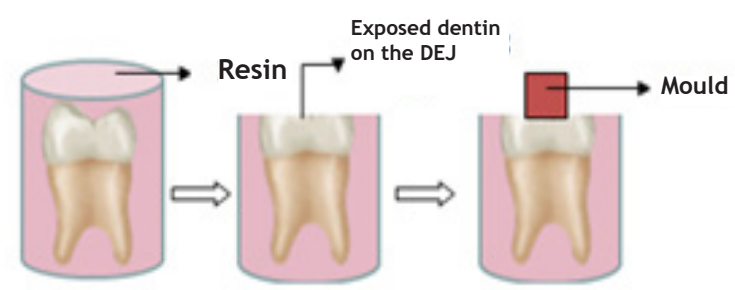

Figure 1. Sample preparation (Personal documentation)

Samples were treated with adhesive system and flowable composite resin according to its manufacture protocol (Group 1 and 2) and without any additional adhesive system for the self-adherent composite resin as instructed from the manufacturer for Group 3. Light curing polymerization of the flowable composite was performed at the minimum distance from the light source (Demi Ultra, Kerr). All restored samples were stored in distilled water for $\mathbf{2 4}$ hours, then subjected for shear bond strength test by universal testing machine (R10Kplus from Llyod Instrument) with $50 \mathrm{kgF}$ at speed $0.5 \mathrm{~mm} / \mathrm{min}$ until bonding failure detected.

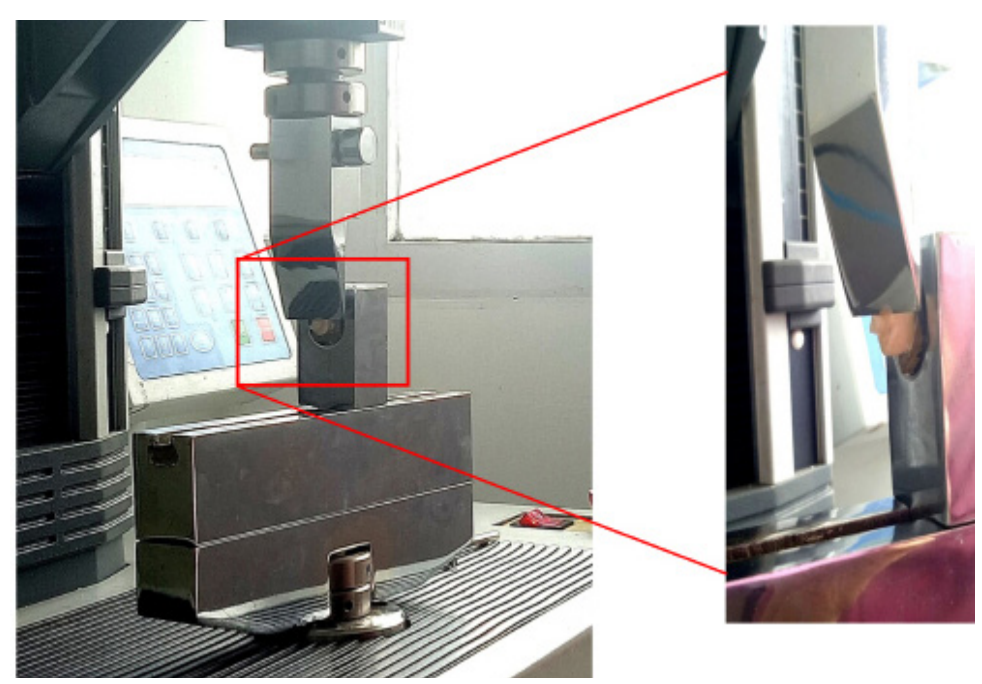

Figure 2. Shear bond strength evaluation by universal testing machine (R10Kplus from Llyod Instrument) with $50 \mathrm{kgF}$ at speed $0.5 \mathrm{~mm} / \mathrm{min}$ 


\section{Statistical analysis}

The data were subjected to statistical analysis using SPSS and were analyzed by one-way ANOVA and Least Significant Difference (LSD) post-hoc test with significance level was set at the $\alpha=0.05$.

\section{RESULTS}

Data from all nine samples in each group were recorded and taken for statistical evaluation. Based on the Shapiro-Wilk test (Table 1), the shear bond strength from each group had normal distribution $(p>0.05)$. The value was further analysed by one-way ANOVA test (Table 2), with no significant differences found in each group $(p>$ 0.05 ), then analysed afterwards with post-hoc LSD for comparing shear bond strength between each group (Table 3).

The mean value from all samples in the three groups and its comparison is shown in Figure 2. The highest bond strength to dentin was seen in Group $1(14.89 \mathrm{MPa})$ followed by Group 2 (11.65 $\mathrm{MPa}$ ) with relative value to Group $3(11.22 \mathrm{MPa})$. No statistically significant were noted for each comparison group.

Table 1. Shapiro-Wilk test of shear bond strength results of the etch and rinse adhesive system, self-etch adhesive system, and self-adherent resin composite

\begin{tabular}{lccc}
\hline \multicolumn{1}{c}{ Groups } & Statistic & df & Sig. \\
\hline Etch and rinse & .934 & 9 & .523 \\
Self-etch & .972 & 9 & .911 \\
Self-adherent & .891 & 9 & .025 \\
\hline
\end{tabular}

Table 2. One-way ANOVA test for each group of the etch and rinse adhesive system, self-etch adhesive system, and self-adherent resin composite

\begin{tabular}{lccccc}
\hline \multicolumn{1}{c}{ Groups } & $\begin{array}{c}\text { Sum of } \\
\text { squares }\end{array}$ & df & $\begin{array}{c}\text { Mean } \\
\text { square }\end{array}$ & F & Sig. \\
\hline $\begin{array}{l}\text { Between } \\
\text { groups }\end{array}$ & 72.405 & 2 & 36.202 & 2.352 & .117 \\
$\begin{array}{l}\text { Within } \\
\text { group }\end{array}$ & 369.475 & 24 & 15.395 & & \\
Total & 441.879 & 26 & & & \\
\hline
\end{tabular}

Table 3. Least Significant Difference (LSD) post-hoc multiple comparisons of etch and rinse adhesive system, self-etch adhesive system, and self-adherent resin composite

\begin{tabular}{|c|c|c|c|c|c|c|}
\hline \multirow{2}{*}{$\begin{array}{l}\text { Adhesive } \\
\text { system (I) }\end{array}$} & \multirow{2}{*}{$\begin{array}{l}\text { Adhesive } \\
\text { system (II) }\end{array}$} & \multirow{2}{*}{$\begin{array}{c}\text { Mean } \\
\text { difference }\end{array}$} & \multirow{2}{*}{ Std. Error } & \multirow{2}{*}{ Sig. } & \multicolumn{2}{|c|}{$95 \%$ confidence interval } \\
\hline & & & & & Lower bound & Upper bound \\
\hline \multirow{2}{*}{ Etch and rinse } & Self-etch & 3.239411 & 1.8496116 & .093 & -.57800 & 7.056822 \\
\hline & Self-adherent & 3.6683889 & 1.8496116 & .059 & -.149022 & 7.485800 \\
\hline \multirow{2}{*}{ Self-etch } & Etch and rinse & -3.239411 & 1.8496116 & .093 & -7.056822 & .57800 \\
\hline & Self-adherent & .4289778 & 1.8496116 & .819 & -3.388433 & 4.246389 \\
\hline \multirow{2}{*}{ Self-adherent } & Etch and rinse & -3.6683889 & 1.8496116 & .059 & -7.485800 & .149022 \\
\hline & Self-adhesive & -.4289778 & 1.8496116 & .819 & -4.246389 & 3.388433 \\
\hline
\end{tabular}

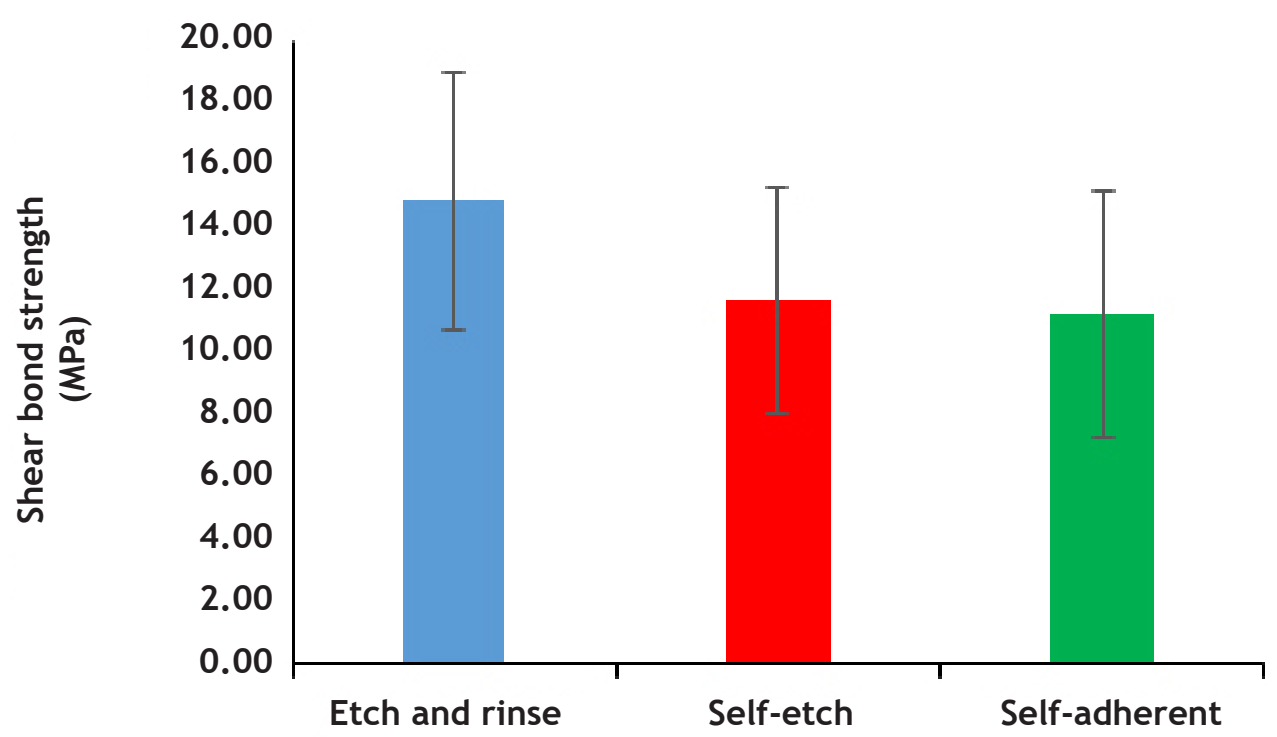

Figure 3. Comparison of the mean value of shear bond strength among groups (post-hoc LSD test) 


\section{DISCUSSION}

In the present study, the composition of the adhesive materials used was considered to be one of the factors that affect the shear bond strength, because other factors such as the type of tooth used as the sample, sample preparation, material application techniques, and sample storage have been controlled. One of the main difference of these three adhesive approaches seems to be on the acidic material used to prepare the tooth surface by dissolving its inorganic component, either by separated high acidic material using $37 \%$ phosphoric acid as in the etch and rinse adhesive system or incorporating the acidic material to the adhesive (self-etch adhesive) or in the composite itself (self-adherent composite resin). The acidic material used in each adhesive system takes part in dissolving the hydroxyapatite structure of the dentin and removing the smear layer that was produced by the preparation procedure. The removal of the smear layer as a whole or part depends on the strength of the $\mathrm{pH}$ of the adhesive material and the rinsing stage that helps to remove the layer. The removal of the smear layer will affect the thickness of the hybrid layer formed between the adhesive material that incorporates and penetrates the dentinal tubules and the complex collagen matrix in the intertubular dentin. The more smear layer removed, the thicker hybrid layer produced. ${ }^{6,10}$

Higher shear bond strength in the etch and rinse group (G1) can be related to the additional etching process creating more surface irregularities. The etch and rinse adhesive system used $37 \%$ phosphoric acid derived from etching. The smaller the acid concentration, the shallower resin tags formed; this affects the bond strength of to the tooth surface because less adhesive material will penetrate to the tags. The $37 \%$ phosphoric acid are capable of dissolving 5-10 $\mu \mathrm{m}$ surface enamel, creating torched areas on the enamel rods in $15-25 \mu \mathrm{m}$ and demineralising dentin up to $7.5 \mu \mathrm{m}$, causing soluble calcium monophosphate after rinsing with water. The etching process on enamel and dentin surfaces creates microscopic surface irregularity, allowing the resin to be mechanically locked on the irregular surface. Based on the SEM evaluation on composite resin restoration using etch and rinse adhesive system, this system produces thick hybrid layers due to complete smear layer loss as a result of the acid etching and flushing process. However, it should be highlighted that the demineralised dentin structure has to be filled with the adhesive to form a hybrid layer. Incomplete infiltration of the adhesive can occur in the demineralised collagen matrix saturated with water. Collagen exposed without hybridisation due to the etching process could lead to post-operative sensitivity. High demineralisation must be followed by the ability of the adhesive/bonding system to penetrate and fill the demineralised area. Therefore, given all the consequences to the exposure of the collagen matrix by phosphoric-acid etching, this approach can be considered as an aggressive procedure to the dentinal structure. ${ }^{3,6,7,9,10}$

The self-etch adhesive system had the second-highest bond value between the tested groups, with no statistically significant with the etch and rinse group. Its bonding property depends on a functional acid monomer, 10-methachryloylozydecyl dihydrogen phosphate (MDP) that interacts with the hydroxyapatite in the tooth. There are two bonding mechanisms of the self-adhesive system; the micromechanical interlocking and chemical bonds that give more value to the durability of this system. The MDP can compete with the ability to etch and rinse using phosphoric acid, due to the interaction of the phosphate group content of MDP to calcium from apatite presented in enamel and dentine forming chemical bonds between the phosphate and calcium ion. Also, mechanical adhesion bonds are achieved through diffusion and polymerization with collagen in dentine producing hybrid layers in the interface. The methacrylate group of the MDP will also polymerize with resin composites. Micromechanical bonding will provide strength to mechanical stress, while chemical interaction will reduce hydrolytic degradation, and keep marginal restoration for long periods. ${ }^{18,19,20,21}$

The lower shear bond strength of the self-etch system compared to etch and rinse adhesive system can also be related to the hybrid layer formation. Based on the SEM evaluation of composite resin restoration using the self-etch adhesive system, the resulting hybrid layer is thinner than that composite resin with an etch and rinse adhesive system. One of the reasons for this 
could be due to the self-etch adhesive material combining the etching of phosphoric acid and the bonding material in one package. Merging these two materials can cause weaker bonding agent penetration into the tooth because the phosphorus and calcium ions produced from the dissolved hydroxyapatite crystals will join the bonding solution. The presence of high concentrations of calcium and phosphorus deposits will limit the further dissolution of hydroxyapatite, thus limiting the depth of teeth demineralisation. ${ }^{10,20}$

The self-adherent composite resin is the newest composite resin where the application is effortless without using an adhesive system, either etching process, primer, or bonding to shorten the working time. Based on SEM evaluation on restoration using self-adherent composite resin, the smear layer visible on the tooth surface is not entirely lost, thus blocking the infiltration of adhesive monomer into dentin tubules and collagen fibres causing the resulting hybrid layer to be thinner than restoration using etch and rinse system. ${ }^{9,10,22,23}$

Similar to the self-adhesive system, the self-adherent composite resin also merged acidic monomer to its resin component. GPDM, which is an active monomer in this type of resin, has a phosphoric acid group for etching and also for forming chemical bonds with calcium ions on tooth surfaces. The self-adherent composite resin has two functional groups of methacrylates as copolymerization with other methacrylate monomers. The monomer aims to increase the density of crosslinking and increase the mechanical strength of the polymerized adhesive so that it has a good ability in adhesion to the tooth surface. However, when compared with the self-etch adhesive system, the self-adherent resin composite has a higher viscosity than the self-etch adhesive system, because fillers load the composite resin. Higher filler components will increase the viscosity that can reduce penetration into the dentin tubule; this explained the lower bond of the self-adherent composite to the selfetch system. However, no significant differences were observed between the two adhesive system; this might be due to the similar pH levels in self-etch adhesive systems and self-adherent composite; 2.5 and 1.9 , respectively. Both pH level incorporated with adhesive only partially removes the smear layer so that some smear layers still cover the dentinal tubules and collagen fibres. ${ }^{13,15}$

Unlike the results of this study, Sachdeva ${ }^{10}$ showed that there was a statistical significance in shear bond strength between self-adherent composite resins and conventional composite resins with etch and rinse adhesive systems in primary teeth. However, the same result was observed between the self-etch compared to etch and rinse adhesive system, where the self-etch system had lower bond strength than the etch and rinse system because it formed thinner and shorter resin tags, this was also observed in this present study. ${ }^{10}$ One approach to improve the adhesive strength of the self-adherent composite resin is scrubbing or polishing the surface of the tooth before the application of the material. Pressure during scrubbing will increase the kinetic energy, which will increase the diffusion of monomer. However, the pressure has the potential to causes damage to collagen tissue, and it will return when the pressure is stopped. At that time, the monomer will penetrate through the collagen tissue and form the hybrid layer. Practitioners can consider this in using a particular type of composite. ${ }^{24}$ Another study evaluated the effect of the application of an adhesive system under self-adhering flowable showed that the application of an adhesive before the self-adherent composite enhanced the bond strength in permanent as well as in primary teeth. In line with the present study, they also resulted in higher bond strength in the self-etch adhesive system followed by conventional resin composite than the self-adherent composite resin. Still, they did not evaluate the etch and rinse system in their study. ${ }^{20}$

The present study showed that in an in vitro condition, all tested groups had comparable bond strength to the dentin surface. However, it should be noted that restoration procedure in the clinical situation will have some other factor that can influence bond strength such as humidity control moisture of the dentin and the present of collagen fibres in the vital tooth that could affect the bonding mechanism.

\section{CONCLUSION}

The etch and rinse adhesive system followed by flowable composite resin have the highest shear 
bond strength to dentin compared to the other groups. However, the shear bond strength is comparable to the self-etch followed by flowable composite resin and the self-adherent composite resin. Therefore, the improved time efficacy and user-friendly property of self-adherent composite resin can be considered as a material of choice in the right case selection.

\section{REFERENCES}

1. Hashimoto $M$, de Gee AJ, Feilzer AJ. Polymerization contraction stress in dentin adhesives bonded to dentin and enamel. Dent Mater. 2008; 24(10): 1304-10. DOI: 10.1016/j. dental.2008.02.008

2. Van Meerbeek B, Peumans M, Poitevin A, Mine A, Van Ende A, Neves A, et al. Relationship between bond strength and clinical outcomes. Dent Mater. 2010; 26(2): e100-21. DOI: 10.1016/j.dental.2009.11.148

3. Van Meerbeek B, Yoshihara K, Yoshida Y, Mine A, De Munck J, Van Landuyt KL. State of the art of self-etch adhesive. Dent Mater. 2011; 27(1): 17-28. DOI: $10.1016 /$ j.dental.2010.10.023

4. Peumans M, De Munck J, Van Landuyt K, Van Meerbeek B. Thirteen-year randomized controlled clinical trial of a two-step self-etch adhesive in non-carious cervical lesions. Dent Mater 2015; 31(3): 308-14. DOI: 10.1016/j. dental.2015.01.005

5. Giannini M, Makishi P, Ayres APA, Vermelho PM, Fronza BM, Nikaido $T$, et al. Self etch adhesive systems: A literature review. Braz Dent J. 2015; 26(1): 3-10. DOI: 10.1590/01036440201302442

6. Garcia RN, Morelli AE, da Silva BS, Giongo $B M$, Pollheim CP, Largura GS, et al. Bonding performance of a self-adhering flowable composite to substrated used in direct technique. Rev Sul Bras Odontol. 2013; 10(4): 343-9.

7. Abdelraouf RM, Mohammed M, Abdelgawad F. Evaluation of shear-bond-strength of dental self-adhering flowable resin-composite versus total-etch one to enamel and dentin surface: An in-vitro study. Open Access Maced J Med Sci. 2019; 7(13): 2162-6. DOI: 10.3889/ oamjms.2019.579

8. Vichi A, Margvelashvili M, Goracci C, Papacchini
F, Ferrari M. Bonding and sealing ability of a new self-adhering flowable composite resin in class I restorations. Clin Oral Investig. 2013; 17(6): 1497-506. DOI: 10.1007/s00784-012-0846-6

9. Poitevin A, De Munck J, Van Ende A, Suyama $Y$, Mine A, Peumans $M$, et al. Bonding effectiveness of self-adhesive composites to dentin and enamel. Dent Mater. 2013; 29(2): 221-30. DOI: 10.1016/j.dental.2012.10.001

10. Sachdeva P, Goswami M, Singh D. Comparative evaluation of shear bond strength and nanoleakage of conventional and self adhering flowable composite to primary teeth dentin. Contemp Clin Dent. 2016; 7(3): 326-31. DOI: 10.4103/0976-237X.188549

11. Peumans M, De Munck J, Van Landuyt K, Van Meerbeek B. Thirteen-year randomized controlled clinical trial of a two-step self-etch adhesive in non-carious cervical lesions. Dent Mater 2015; 31(3): 308-14. DOI: 10.1016/j. dental.2015.01.005

12. Burke FJT, Hussain A, Nolan L, Fleming GJP. Methods used in dentine bonding tests: An analysis of 102 investigations on bond strength. Eur J Prosthodont Rest Dent. 2008; 16(4): 158-65.

13. van Dijken JWV, Pallesen U. Eight-year randomized clinical evaluation of class II nanohybrid resin composite restorations bonded with a one-step self-etch or a twostep etch-and-rinse adhesive. Clin Oral Investig. 2015; 19(6): 1371-9. DOI: 10.1007/ s00784-014-1345-8

14. Boushell LW, Heymann HO, RitterAV, Sturdevant JR, Swift Jr EJ, Wilder Jr AD, et al. Six-year clinical performance of etch-and-rinse and self-etch adhesives. Dent Mater. 2016; 32(9): 1065-72. DOI: 10.1016/j.dental.2016.06.003

15. Yamauchi K, Tsujimoto A, Jurado CA, Shimatani $Y$, Nagura $Y$, Takamizawa T, et al. Etch-and-rinse vs self-etch mode for dentin bonding effectiveness of universal adhesives. J Oral Sci. 2019; 61(4): 549-53. DOI: 10.2334/ josnusd.18-0433

16. Sugimura R, Tsujimoto A, Hosoya $Y$, Fischer NG, Barkmeier WW, Takamizawa T, et al. Surface moisture influence on etch-and-rinse universal adhesive bonding. Am J Dent. 2019; 32(1): 33-8.

17. Boushell LW, Heymann HO, Ritter AV, Sturdevant 
JR, Swift Jr EJ, Wilder Jr AD, et al. Six-year clinical performance of etch-and-rinse and self-etch adhesives. Dent Mater. 2016; 32(9): 1065-72. DOI: 10.1016/j.dental.2016.06.003

18. Shafiei F, Saadat M. Micromorphology and bond strength evaluation of adhesive interface of a self-adhering flowable composite resindentin: Effect of surface treatment. Microsc Res Tech. 2016; 79(5): 403-7. DOI: 10.1002/ jemt.22643

19. Peterson J, Rizk $M$, Hoch $M$, Wiegand A. Bonding performance of self-adhesive flowable composites to enamel, dentin and a nanohybrid composite. Odontology. 2018; 106(2): 171-80. DOI: $10.1007 / \mathrm{s} 10266-017-0324-3$

20. Tuloglu N, Tunc ES, Ozer S, Bayrak S. Shear bond strength of self-adhering flowable composite on dentin with and without application of an adhesive system. J Appl Biomater Funct Mater. 2014; 12(2): 97-101. DOI: 10.5301/

\section{jabfm.5000166}

21. Giannini M, Makishi P, Ayres APA, Vermelho PM, Fronza BM, Nikaido T, et al. Self etch adhesive systems: A literature review. Braz Dent J. 2015; 26(1): 3-10. DOI: 10.1590/01036440201302442

22. Tulunoglu 0 , Tulunoglu I. Resin-dentin interfacial morphology and shear bond strengths to primary dentin after long-term water storage: $A n$ in vitro study. Quintessence Int. 2008; 39(5): 427-37.

23. Malhotra N, Mala K. Light-curing considerations for resin-based composite materials: A review. Part I. Compend Contin Educ Dent. 2010; 31(7): 498-505.

24. Reis A, Pellizzaro A, Dal-Bianco K, Gones OM, Patzlaff R, Loguercio AD. Impact of adhesive application to wet and dry dentin on longterm resin-dentin bond strengths. Oper Dent. 2007; 32(4): 380-7. DOI: 10.2341/06-107 